\title{
Philosophy of technology: performance review and expected development
}

\author{
Elena Papchenko ${ }^{1}$, Ruslan Bazhenov ${ }^{2 *}$, Emma Bestaeva $^{3}$, and Sergey Bogatenkov ${ }^{4}$ \\ ${ }^{1}$ Southern Federal University, 344006, Rostov-on-Don, Russia \\ ${ }^{2}$ Sholom-Aleichem Priamursky State University, 679016, Birobidzhan, Russia \\ ${ }^{3}$ North-Osetian State University named after K.L.Khetagurov, 362025, Vladikavkaz, Russia \\ ${ }^{4}$ South Ural State University, 454080, Chelyabinsk, Russia
}

\begin{abstract}
The paper is related to viewing the genesis and prospects for the development of one of the most important branches of philosophy - the philosophy of technology. The authors begin their survey with the time when a grounding of the philosophy of technology was given, i.e. when technology became comprehensible in terms of a philosophical and philosophical point of view until such extended studies concerned to the technology that developed into one of the most dominating factors in social development. It is reported that exact antipodes of opinion were made up in the classical philosophy of technology. Criticism of technology lasted long till its sacral significance and understanding technological reality requirements. Finally, it culminated in creating various approaches to study technology: engineering, humanitarian, social and philosophical. However, a pragmatic approach to the technology observation and development outcomes developed gradually. The paper comes to the point that contemporary philosophy of technology is harmonious and holistic in nature.
\end{abstract}

\section{Introduction}

Since the Ancient times, many philosophers focused on various aspects of technology. However, a systematic study of technology from a philosophical point of view dates back to the $19^{\text {th }}$ century, and the development of philosophy of technology goes to the second half of the $20^{\text {th }}$ century.

Philosophers of various currents of thought (traditions) have already intensified their efforts to understand the issues related to technological advances. K. Jaspers, M. Heidegger, representatives of the Frankfurt School classify technology as a means that not only changed a human daily life fundamentally, but also influenced generally the development of Reform (Modernization) Age that was destructive [1].

Modern philosophers and researchers also emphasize the conflict between human spirituality and the products of a man's practical and technical creativity $[2,3]$.

C. Chen and Q. Wang admit [4] the necessity to take into account the fact that keeping a stable balance depends only on a person.

*Corresponding author: r-i-bazhenov@yandex.ru 
Today's life stage of human development determines human responsibility for their own future, shows an unusually delicate balance that separates a human being from further processes of his technological reformation. M. Coeckelbergh [5], D. Ihde [6], A.K. Tripathi [7] draw attention to their feedback effects.

The fact that not only regarding the relationship between man and technology, nature and technology is the centerpiece, but also the larger relationship of cultural changes, which include the transformation of way of thinking influenced by the latest technological developments [8] is emphasized in present-day studies dedicated to the development of technological reality.

The authors can also talk about the laws of technological evolution taking into account the development of technology and broadened reality generated by it. It lies in the fact that, firstly, technological reality (the accomplished transformation of biosphere into technosphere) has become universal and man can no longer survive outside (and without) the technological world around him [9]. Secondly, the hierarchical complication of the technological world occurred reflected the fact that today man's survival does not depend on his individual tools and artifacts, but exists only as a part of technocenosis. Thirdly, the global technological evolutionism calls for another technological one. As an expected result, this poses the question of possible changing of anthropocentrism as a paradigm to technocentrism as a belief system.

This issue is particularly relevant in connection with the processes of combining science and technology, which causes a number of new epistemological (gnosiological) problems that demand their special consideration urgently [10].

So, in the US philosophical thought, research on the philosophy of technology is traditionally carried out in the course of the national program Science, Technology, Society $(S T S)$. Over the past years, discussions have been held about the interconnected development of science and technology as kinds of present-day human activity and the contribution they make to modern industrial civilization. At present, when science and technology are given mixed and contradictory assessment, STS faces a number of challenges. These include making a practical contribution to the relationship between science and society and controlling pragmatic technocracism [11].

This situation drives the need to coordinate the efforts of representatives of humanities and technical sciences, and promote interdisciplinary research.

This study is aimed both at analyzing systematized knowledge by means of the philosophy of technology, and studying current scientific field in the development of the philosophy of technology.

\section{Fundamentals of systematic study of technology}

Under very general approach concerning the philosophy of technology, the authors can note the following: firstly, understanding technology has already been observed since antiquity in attempting to solve the problem. Secondly, a tendency to follow a systematic philosophical methods to study technology was developed only at the end of the $19^{\text {th }}$ and beginning of the $20^{\text {th }}$ centuries. In the history of philosophy, various view points of the origin of technology have developed so far. It highlights that researchers have different understanding of this phenomenon.

When getting down to determining the notion of technology, the authors point out that this is a system of material instruments, knowledge and skills used to obtain definite results and characterized by anthropogenic origin and reproducibility [12]. In the philosophy of technology, the concept of technology is not used to define certainly perceived mechanisms, machines and construction works, but is considered to be a subjectified form of naturalistic views, ideas, engineering, and different sociocultural surrounding. Therefore, 
the genesis should be said to sum up a rational redevelopment of all components recognized [13].

For the first time, ideas concerning technology were discussed in ancient culture, and it was at the time when, although, there was no substantial interaction between science and technology, understanding technology developed scientifically in a certain sociocultural environment.

The attempts to include the science-based sense into the concept of technology gradually led to formatting technology as a relatively independent knowledge system. It happened in Modern history (the modern period, the modern era, or modern times). In the second half of the $19^{\text {th }}$ century a philosophical understanding of technology was established. According to it, equipment and machines are a continuation to enhancing functions of human organs or organic (constitutional) projections. 'The importance of organic projection principle has become more apparent since cybernetics, robotics appeared, and modern biotechnologies developed' [14].

A. Lazarevich showed a modern tendency focusing on interdependence of improving technology and its similarity with a living organism or its individual parts and functions. It is based on bridging a technical and biological gap catering to creating biological through artificial. An example of such a synthesis and potential opportunities of interaction are nano-technologies, bio- and genetic engineering. These fields predetermine developing such fields as Nano biotechnology, which allow 'reproducing the world around using the same techniques that nature does by itself' [15].

The idea of technology was influenced by engineers who "were involved directly in scientific and technological advance, in generation and development of industrial capitalism when a technological value increased dramatically at the end of the $19^{\text {th }}$ century' [16]. In the present circumstances, technology has become a tool in the fight for profit. In its turn, it caused changes of a production pattern, the social structure of society and people's way of living, as well as social values. In other words, technology is a necessary requirement for the Western world development. It is a matter of fact that in this context, the phenomenon of technology has to be analyzed philosophically.

The philosophical understanding of technology became much more meaningful in the first half of the $20^{\text {th }}$ century. At the same time, two approaches to understanding technology were clearly differentiated. They were engineering and humanitarian ones.

An engineering approach to technology should be aimed at revealing the matter of the technical way of human's being in the world, which is the main one for understanding other types of human reasoning and acting. This approach is followed by E. Kapp, P.K. Engelmeyer, F. Dessauer and others.

As for a conceptual approach to assessing technology, it corresponds to a humanitarian approach shared by K. Jaspers, L. Mumford, J. Ortega y Gasset and others. Unlike an engineering approach, there are systematic attempts prevailing to defend the priority of humanitarian, non -technical basis over technical one.

Modern philosophy of technology proposes a new way to percept it. It is a social and philosophical approach.

From the point of view of the socio-philosophical approach, the notion of technology 'features not only a combination of tools (created by people to meet the needs accepted by collective consciousness and used according to social codes), but also sociocultural codes of work with natural reality (through processing it into artificial reality by means of technical practice) and meant subjectively in this process of senses by man' [17].

The socio-philosophical approach to technology is based on a number of theses. Firstly, forms and methods of creating and mastering technical objects available in a given society are determined socially. Secondly, technological progress is determined by social arrangements. Thirdly, a specific contribution of one or another society to the development 
of technology depends on social environment [18]. Fourth, the assessment of technological impact on a society should take into account technological changes in cultural codes that control social relations $[19,20]$. And fifth, the very functioning of a social system can be interpreted as a technology and analyzed using concepts developed to analyze technology [17].

\section{Philosophy of technology: current development trends}

The structure of philosophy based on unbiased findings allows the authors to consider the philosophy of technology as one of the most important branches of philosophy. The current philosophy of technology is divided into large sections of ranges of philosophical problems covering: a) the philosophy of technology itself; b) philosophical issues of technology; c) social and philosophical aspects of technology; d) philosophical issues of engineering; e) philosophical issues of technical and engineering sciences [21].

The main trend was a correlation of technology and culture while developing the philosophy of technology. It met the needs of rapidly developing self-consciousness of the engineering community [22]. Beyond being interested in the philosophy of technology, society has been more engaged and concerned about its interaction with the philosophy of science since the mid- $20^{\mathrm{th}}$-century. Firstly, society was dealing with studying correlation between science and technology. Secondly, it was discussing methodological issues.

Nowadays, a new trend has developed in the philosophy of technology regarding sociophilosophical, political science and ethical problems of modern technology.

Such a focus on the philosophy of technology distinguishes a quality change in the main tasks of it.

The first task is to attempt to refer to the study of the subject matter of technology, to estimate the extensive changes in understanding technology caused by the expansion of industrial civilization in the course of the philosophy of technology.

In this respect, the question of a moral view now arises. The moral view was added without prior arrangement to an optimistic perception of the synthesis of technical and social progress that developed at in the early days of industrial society [23]. The development level achieved in science and technology invented on scientific foundation insist on a serious philosophical analysis of the links between improving technicality of human life and human spiritual dimension development. It is caused by the fact that today's products of technical sciences not only expand the boundaries of human opportunities essentially. They also require answering the question about what spiritual and moral qualities are of those who produces and uses these products. It is not by chance that there is a trend that becomes more popular in society. It illustrates the illusory nature of hopes of a favorable solution to the problems of man and society that are put on science and technology. On the contrary, the previous social mind rush that the further scientific and technological development will solve the mankind's problems is replaced by the claims that scientific and technological progress that is not guided by moral principles will cause the destruction of the very type of spiritualized personality.

The second task following from the first one is to look for the ways to cope with the crisis.

A. Grunwald reports on an ethical imperative, concluding that expectations of technological progress should be accompanied by the principle of responsibility [24]. Mastering a set of modern advanced technologies by mankind can increase human capabilities much. Therefore, it results in taking shared responsibility as something natural and necessary.

For which reason, H. Lenk and M. Maring emphasize that all particular participants (technicians, engineers, philosophers of nature) have to take responsibility, but 
nevertheless, they are not the only ones who must be in charge of moral responsibility for the application of their inventions [25].

One might as well say that the following trends are representative in modern philosophy of technology. The first one is an empirical approach related to the philosophers' change in interest from the analysis of using technology and its social outcomes towards the study of its development and growing influence. The second one is an axiological approach which stands for the philosophical self-reflection of value-based foundations of technical and engineering practice. The third one is the continuing discussion about the subject matter of technology, taking into account the challenges that the latest technologies offer. The fourth one is a number of classical ideas to be re-thought. Above all things, it is the concept of human nature provoked by a philosophical movement of transhumanism. In this context, the applied and research aspect is prevailing in modern philosophy of technology [26].

\section{Conclusion}

The philosophical thought of technological reality took a long time to be developed and resulted in generating various approaches to its investigation: engineering, humanitarian, social and philosophical. Engineering approach deals with revealing the subject matter of technics of human being on earth. The humanitarian approach considers technology in terms of having priority of a non-technical basis over a technical one. Socio-philosophical approach is a reflected combination of 1 ) human needs accepted by public opinion (social mind) to be met and created by people and tools used according to the social code; 2) social and cultural codes of dealing with natural reality; 3) meanings intended individually by a person in this process.

A focus of contemporary philosophy of technology takes into account present-day challenges and axiological issues are dominating progressively in science.

The applied and research aspect prevails in contemporary philosophy of technology. It covers specific problems and potential collisions appropriate to both the property of technology and technical work.

A new trend is developed in the philosophy of technology. It involves sociophilosophical, politological and ethical issues of current technology.

The priority in technology research should be an integration of science, economics, and politics.

\section{References}

1. Z. Kádár, J.I. Tóth, Procedia-Social and Behavioral Sciences, 71, 53 (2013)

2. P.P. Verbeek, Moralizing technology: understanding and designing the morality of things (University of Chicago Press, Chicago, 2011).

3. B. Irrgang, Handling technical power: philosophy of technology (Franz Steiner Verlag, Stuttgart, 2014)

4. C. Chen, Q. Wang, Technology in Society, 43, 57 (2015)

5. M. Coeckelbergh, Foundations of Science, 22, 339 (2017)

6. D. Ihde, Technology and the Lifeworld: From Garden to Earth (Indiana University Press, Bloomington, 1990)

7. A.K. Tripathi, Information Cultures in the Digital Age (Springer VS, Wiesbaden, 2016).

8. T.P. Mal'kova, Manuskript, 79 (2018) 
9. B.I. Kudrin, Technetics: a New paradigm of the philosophy of technology (the third scientific picture of the world) (Tomsk University publishing house, Tomsk, 1998).

10. V. Gorokhov, History of Mechanism and Machine Science, 27, 207 (2015)

11. I.T. Kasavin, Social philosophy of science and collective epistemology (Ves' Mir, Moscow, 2016)

12. Dictionary of philosophical terms (Infra-M, Moscow, 2004).

13. V.G. Gorokhov, V.M. Rozin, Introduction to the philosophy of technology (Infra-M., Moscow, 1998)

14. T.A. Il'ina, News of Moscow state industrial university, 4, 26 (2008)

15. A. Lazarevich, Science and innovation, 3, 22 (2014)

16. O.F. Tereshkun, Volga scientific bulletin, 46 (2013)

17. N.V. Popkova, Philosophy of science and technology, 23, 49 (2018)

18. M. Coeckelbergh, Technology in Society, 52, 4 (2018)

19. A.K. Tripathi, AI \& Society, 32, 137 (2017).

20. A. Borgmann, Educational Technology, 52, 40 (2012)

21. M.A. Baryshev, Subject of philosophy of technology, Abstract of Ph.D. dissertation, (Krasnoyarsk, 2006).

22. V.G. Gorokhov, Voprosy Filosofii, 178 (2014)

23. V.V. Cheshev, Voprosy Filosofii, 64. (2017)

24. A. Grunwald, GAIA-Ecological Perspectives for Science and Society, 24, 249 (2015)

25. H. Lenk, M. Maring, Interdisciplinary Science Reviews, 21, 316 (1996)

26. D.K. Kulikov, All-Russian scientific and practical conference dedicated to the memory of I. A. Negodaev (Don state technical university, Rostov-on-Don, 2018) 